\title{
Optical Display of Transverse Jet Flow Field Under Supersonic Inflow
}

\author{
Qian LI , Ji-fei Ye, Dian-kai Wang \\ State Key Laboratory of Laser Propulsion \& Application, Equipment Academy, Beijing 101416, China
}

\begin{abstract}
Optical display and measurement of transverse jet flow field under supersonic inflow is performed with continuous xenon lamp color schlieren, strobo light color schlieren and strobo light monochrome schlieren. Characteristic of fuel transverse jet in scramjet combustion chamber is studied. Results indicate that wave structure can be displayed through images obtained from long time exposure of schlieren, exposure time in dozens of nanoseconds is suitable for the display of turbulent structure, and comparing with color schlieren, amounts of information obtained from monochrome schlieren are few, whose sensitivity is much lower, either.
\end{abstract}

\section{Introduction}

Ignition, flame holding and fuel mixing are primary problems in supersonic combustion. When vehicle flights in supersonic/hypersonic speed, velocity of gas entering into the combustion chamber is high, and the retention time is very short, so the promotion of propulsion system performance is restricted. Therefore, high performance propulsion system needs promoting mixture degree of fuel and air. Less drag loss is better with fuel jet, and favorable fuel distribution should be formed on cross section of combustion chamber.

Combustion efficiency of scramjet is directly influenced by transverse jet characteristic of fuel ${ }^{[1]}$. Study on the characteristic of transverse jet flow under supersonic condition is helpful to the structure designing of combustion chamber, confirming the igniting position and igniting mode of scramjet ${ }^{[2]}$. As a non-contacting optical display and measurement technology, schlieren would not interfere the flow field, and can reflect density variation of the fluid directly, so it is widely applied in the measurement of high-velocity flow field. Color schlieren is one of the schlieren techniques which is paid much attention to. A. K. Agrawal et al. ${ }^{[3-8]}$, G. E. Elsinga et al. ${ }^{[9]}$ and DLR Aerospace Center ${ }^{[10]}$ are well known of their research on color schlieren technique.

For studying the distribution of fuel after it is injected into the combustion chamber and the interaction between fuel and supersonic inflow, optical display and measurement of transverse jet flow field under supersonic inflow is performed with continuous xenon lamp color schlieren, strobo light color schlieren and strobo light monochrome schlieren, so as to choose the appropriate optical display and measurement technique according to different requirements in further study.

\section{Experimental measurement}

system

and

\subsection{Experimental table}

Experimental table is composed of supersonic flow table and transverse jet, whose photo is shown in Figure1.

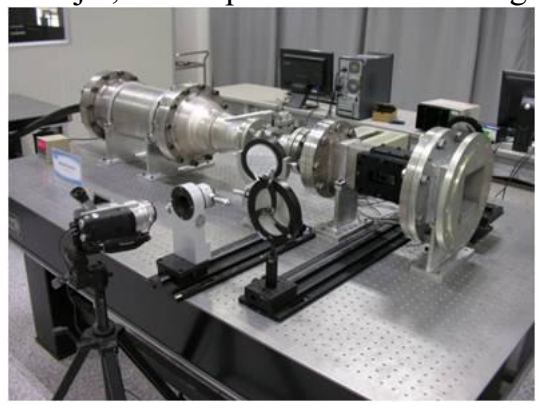

Figure 1. Photo of experimental table

Mach number of the supersonic flow is 2.5 , mass flow is $0.5 \mathrm{~kg} / \mathrm{s}$, test time is $1 \mathrm{~s}$, and the total pressure of transverse jet is $1 \mathrm{MPa}$. Cross section of the transverse jet is circular, whose exit diameter is $\Phi 2 \mathrm{~mm}$.

\subsection{Schlieren technique}

Photo of schlieren measurement system is shown in Figure 2.

Color schlieren and monochrome schlieren are both adopted in the experiment. In order to display different wave structure system, three schlieren techniques are used. 


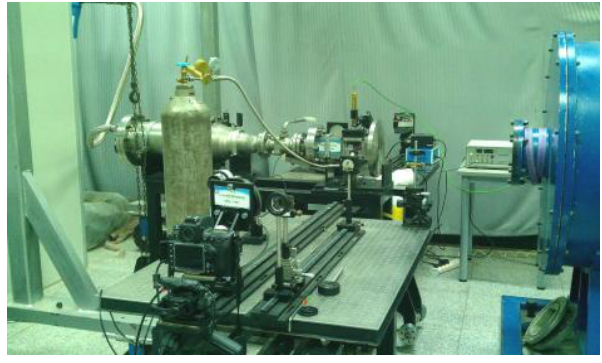

Figure 2. Photo of schlieren measurement system

\section{Three schlieren techniques and optical display}

\subsection{Continuous xenon lamp color schlieren}

For displaying the structure of shock wave, continuous xenon lamp color schlieren is used in the measurement. The exposure time is $2 \mathrm{~ms}$, and the experimental photos are shown in Figure 3.

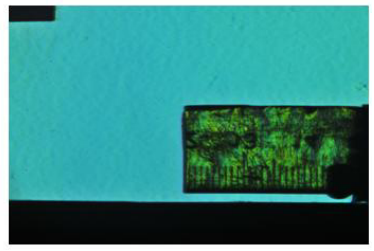

(a)original image of scale

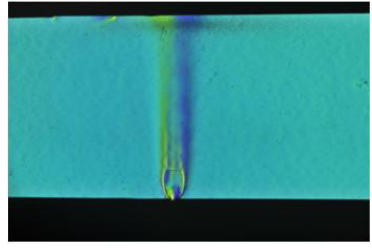

(b)original image of transverse jet

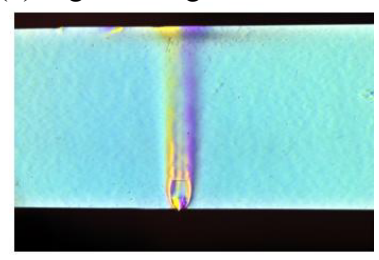

(c)image of transverse jet with hue disposal

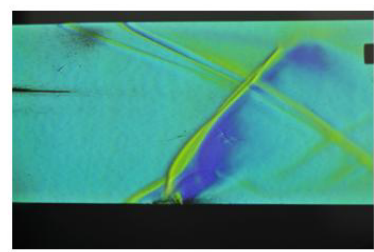

(d)original image with inflow

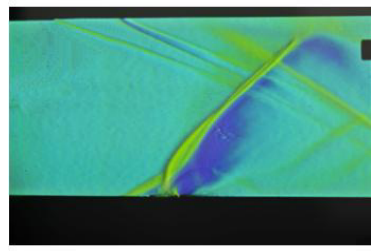

(e)image with greasy dirt disposal

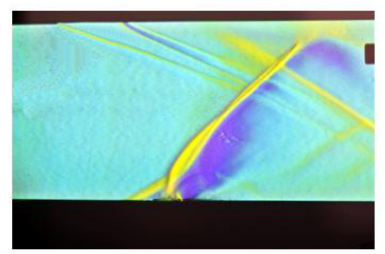

(f)image with hue and greasy dirt disposal

Figure 3. Photos taken by continuous xenon lamp color schlieren

\subsection{Strobo light color schlieren}

For displaying structure of turbulence, strobo light color schlieren is used in the measurement. The exposure time is $100 \mathrm{~ns}$, and the single flash time of light source is 20ns. Schlieren photo of transverse jet is shown in Figure 4. The photos is hue disposed. From the amplifying photo, it can be seen that the structures of turbulence and shock wave are both obvious.
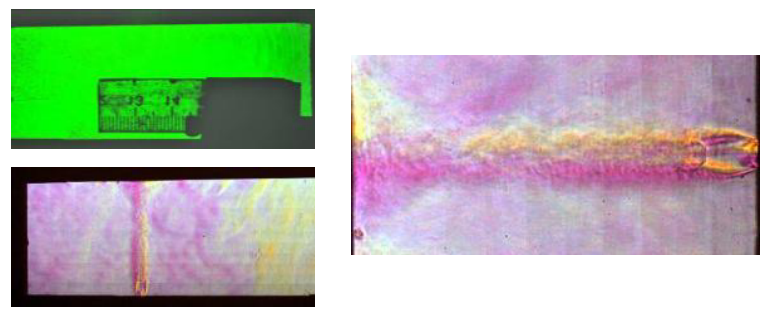

Figue 4. Schlieren photo of transverse jet
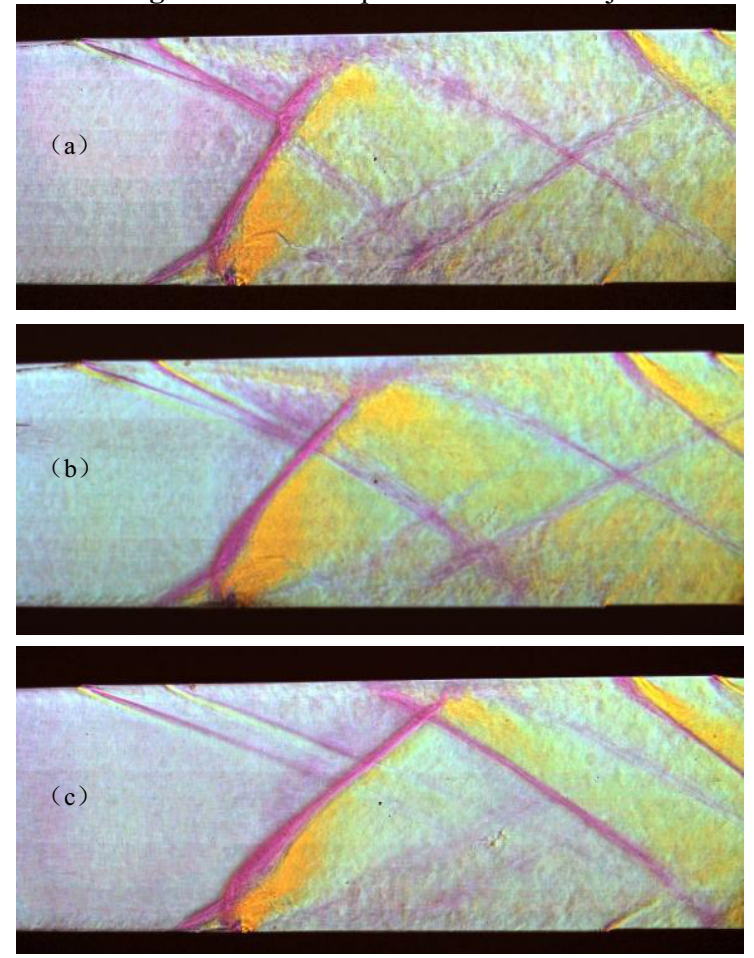

Figure 5. Schlieren photos under different inflow speeds with the start-up of wind tunnel

Schlieren photos under different inflow speeds with the start-up of wind tunnel are shown in Figure 5. From 
the oblique angle of the second shock wave on the upper wall and the turbulent structures after the shock, it can be concluded that the inflow speed is becoming faster from Figure 5(a) to Figure 5(c). The situation of total start-up of the wind tunnel is shown in Figure 5(c), and the mach number is 2.5. There are shock structures in Figure 5(a) and Figure 5(b), so the inflow speed is supersonic too. It is worth to notice that in Figure 5(a) and Figure 5(b), when the inflow speed is relatively low, mach disk, bulk shock and large scale turbulent structures are more obvious.

\subsection{Strobo light monochrome schlieren}

In measurements with strobo light monochrome schlieren, the exposure time is 20ns and high speed enhancing camera is adopted. Typical result obtained by strobo light monochrome schlieren with greasy dirt disposal is shown in Fig .6.

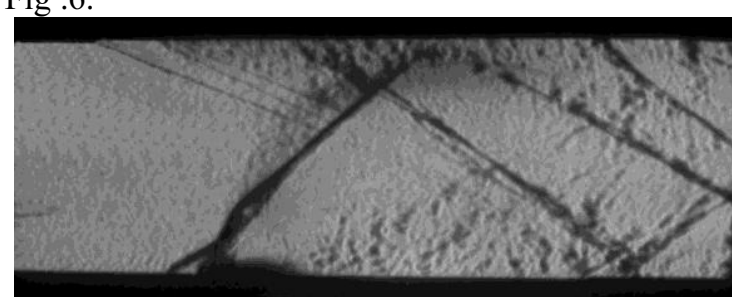

Figure 6 Photo taken by strobo light monochrome schlieren

It can be seen that there is bulk shock in Figure 6, but not obvious, and large scale vortexes are in disorder. Information obtained from monochrome schlieren is less than that of color schlieren. Comparison between typical result in this paper and that of references is shown in Figure 7.

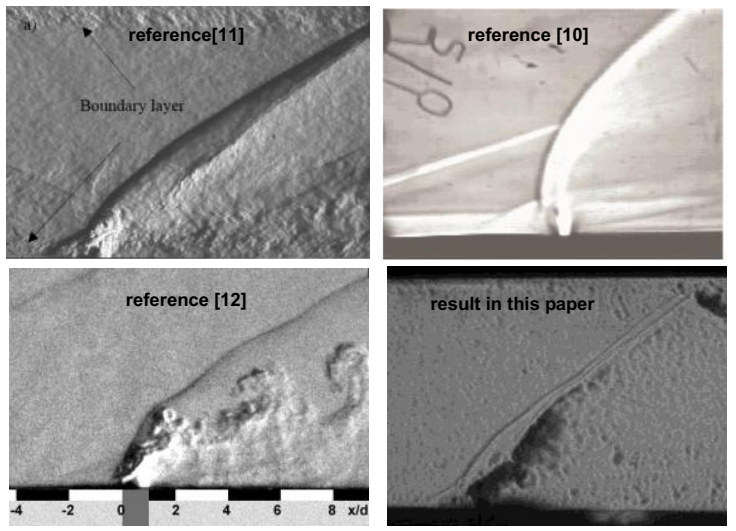

Figure 7 Comparison between our result and references

Table 1. Parameters of the experimental table in reference ${ }^{[11]}$ and ours

\begin{tabular}{|c|c|c|}
\hline $\begin{array}{c}\text { parameters of experimental } \\
\text { table }\end{array}$ & $\begin{array}{c}\text { reference } \\
{[11]}\end{array}$ & $\begin{array}{c}\text { our experimental } \\
\text { table }\end{array}$ \\
\hline total pressure of free inflow & $279 \mathrm{kPa}$ & $400 \mathrm{kPa}$ \\
\hline $\begin{array}{c}\text { boundary layer thickness of } \\
\text { free inflow }\end{array}$ & $3.2 \mathrm{~mm}$ & $\approx 3 \mathrm{~mm}$ \\
\hline mach number of free inflow & 2.25 & 2.5 \\
\hline total pressure of transverse jet & $378 \mathrm{kPa}$ & $1 \mathrm{MPa}$ \\
\hline $\begin{array}{c}\text { momentum ratio between } \\
\text { transverse jet and free inflow }\end{array}$ & 1.7 & 3.7 \\
\hline
\end{tabular}

\begin{tabular}{|c|c|c|}
\hline $\begin{array}{c}\text { exit mach number of } \\
\text { transverse jet }\end{array}$ & 1 & 1 \\
\hline exit diameter of transverse jet & $4.8 \mathrm{~mm}$ & $2 \mathrm{~mm}$ \\
\hline
\end{tabular}

It should be noticed that cold flow tunnel is used in reference ${ }^{[11]}$, but in reference ${ }^{[12]}$ high enthalpy expanding tube is adopted(total enthalpy is $4 \mathrm{MJ} / \mathrm{kg}$ and inflow mach number is 3.5), and in reference ${ }^{[10]}$, exit speed of transverse jet is supersonic, not sonic. Parameters of the experimental table in reference ${ }^{[11]}$ and ours are shown in Table 1.

\section{Conclusion}

1)Wave structures, such as bow shock, separate shock, bulk shock and mach disk, can be displayed by schlieren technique with long time exposure. But for mixed layer boundary, compressive wave, boundary layer and trail, it is unfavorable.

2)Dozens of nanoseconds exposure time of schlieren is suitable for the display of turbulent structure, especially measured by color schlieren, disordered state of turbulence can be clearly observed.

3)Compared with color schlieren, information obtained from monochrome schlieren is much less, and the sensitivity is much lower too. However, if the knife edges is more enough, theoretically to say, bulk shock structure and the mixed area can also be observed. Otherwise, difference between bow shock and mixed layer boundary can be recognized in monochrome schlieren which is difficult to be distinguished in color schlieren because of its high sensitivity.

\section{Acknowledgement}

This research was supported by the Natural Science Foundation of China (11372356, 11372357).The authors would like to acknowledge all discussions and technical help provided by the former and current members of the State Key Laboratory of Laser Propulsion and Application.

\section{References}

1. T. H. Chen, C. R. Smith and D. G. Schommer. Multi-zone behavior of transverse liquid jet in high-speed flow[R]. AIAA 1993-0453.

2. Y. H. Tong. Injection characteristic and breakup process of transverse liquid jet in crossflow[D]. Changsha: National University of Defense Technology, 2012.

3. Agrawal, K. Alammar, and S. Gollahalli. Application of rainbow schlieren deflectometry to measure temperature and oxygen concentration in a laminar gas-jet diffusion flame[J]. Experiments in Fluids, 2002, 32(6): 689-691.

4. S. Yildirim and A. Agrawal. Full-field measurements of self-excited oscillations in momentum-dominated helium jets[J]. Experiments in Fluids, 2005, 38(2): 161-173.

5. T. Wong and A. Agrawal. Quantitative measurements in an unsteady flame using high-speed rainbow schlieren deflectometry[J] Measurement Science and Technology, 2006, 17(6): 1503-1510.

6. P. Kolhe and A. Agrawal. Role of buoyancy on 
instabilities and structure of transitional gas jet diffusion flames[J] Flow Turbulence and Combustion, 2007, 79(4): 343-360.

7. R. Satti, P. Kolhe, S. Olcmen, and A. Agrawal. Miniature rainbow schlieren deflectometry system for quantitative measurements in microjets and flames[J]. Applied Optics, 2007, 46(15): 2954-2962.

8. P. Kolhe and A. Agrawal. Density measurements in a supersonic microjet using miniature rainbow schlieren deflectometry[J]. AIAA Journal , 2009, 47(4): 830-838.

9. G. E. Elsinga, B. W. van Oudheusden, F. Scarano and D. W. Watt. Assessment and application of quantitative schlieren methods with bi-directional sensitivity: CCS and BOS[C]. Proceedings of PSFVIP-4 June 3-5, 2003, Chamonix, France.
10. D. Herrmann, W. W. Koschel. Experimental investigation of the internal compression of a hypersonic intake[C], 38th AIAA/ASME/SAE/ASEE Joint Propulsion Conference \& Exhibit 7-10 July 2002, Indianapolis, Indiana.

11. L. Eli, G. Elliott, N. Glumac. Energy deposition applied to a transverse jet in a supersonic crossflow[R]. AIAA 20091534.

12. A. Ben-Yakar. Experimental investigation of mixing and ignition of transverse jets in supersonic crossflows[D]. Stanford University, 2001. 